\title{
A Novel Thick-Film Screen Printed Electrical Conductivity Sensor for Measurement of Liquid and Soil Conductivity
}

\author{
John K. Atkinson \& Marios Sophocleous \\ Faculty of Engineering \& the Environment \\ University of Southampton \\ Southampton, United Kingdom \\ Email: jka@soton.ac.uk
}

\begin{abstract}
Results are reported from an initial evaluation of a novel conductivity sensor that has been incorporated onto a multi-element thick film sensor array designed for soil and water analysis. The new sensor exhibits a more repeatable cell constant of approximately $0.15 \mathrm{~cm}^{-1}$ over a wider range of conductivities compared with conductivity sensor designs previously employed in the sensor array. The new sensor is currently performing very well in an investigation of soil structural properties where its output is being correlated with soil water content in a study of different soil porosities.
\end{abstract}

Keywords-Thick Film Sensors, Electrical Conductivity, Cell Constant, Four Electrodes Method.

\section{INTRODUCTION}

Increasing interest in optimal environmental management, site-specific crop management (SSCM) and climate impact on soil behaviour have all resulted in a rising demand for in-situ soil sensing among many environmentalists and soil scientists. Floodplain ecosystems are dependent on the specific hydrological regime but the mechanisms controlling species composition of the hydrological regime and related temperature and nutrient levels have not yet been fully understood [1]. SSCM, also called precision agriculture, evaluates variability in soil properties (e.g., $\mathrm{pH}$, temperature, organic matter, water content and soil nutrient levels) to optimize inputs such as fertilizers and herbicides for an optimised agricultural growth [2]. Specific soil parameters and their critical limits are considered to reflect the impact of the climate on soil behaviour [3] and require monitoring to identify changes in soil quality which will provide the basis of understanding some of nature's unknown mechanisms for various agroecological zones at district, national and global levels [4]. Low cost, miniaturised electrochemical and physical sensors with modest electronic instrumentation demands that can be buried in the soil will allow for an online high density sensor network providing vital data information for the understanding of climate impact on soil behaviour and furthermore on an area's ecosystem. Measuring soil conductivity can provide vital information on the water content of the soil as well as distinguishing between different types of soil (e.g. clay, gravel, sand, limestone, coal and several combinations of them) [5-6].

Conductivity readings combined with porosity measurements can give information on the stability of the ground [7-8] which is extremely important in applications such as train rail supporting structures. Although several conductivity probes are available commercially, the cost of such probes including the instrumentation required to take the readings does not allow for a feasible high density sensor network [9-11]. Thick Film (TF) conductivity sensors are of low cost, rugged, miniature and robust design and have the ability to be integrated onto a single substrate with other sensors forming a lab-on-a-chip sensing array. In addition, due to the sensor design the required electronic interface is of low complexity which provides the opportunity for a higher density sensor network in the investigation area [12]. A typical device is shown in Figure 1 where planar conductivity measuring electrodes have been incorporated onto a multi-element sensor array for monitoring soil and water properties.

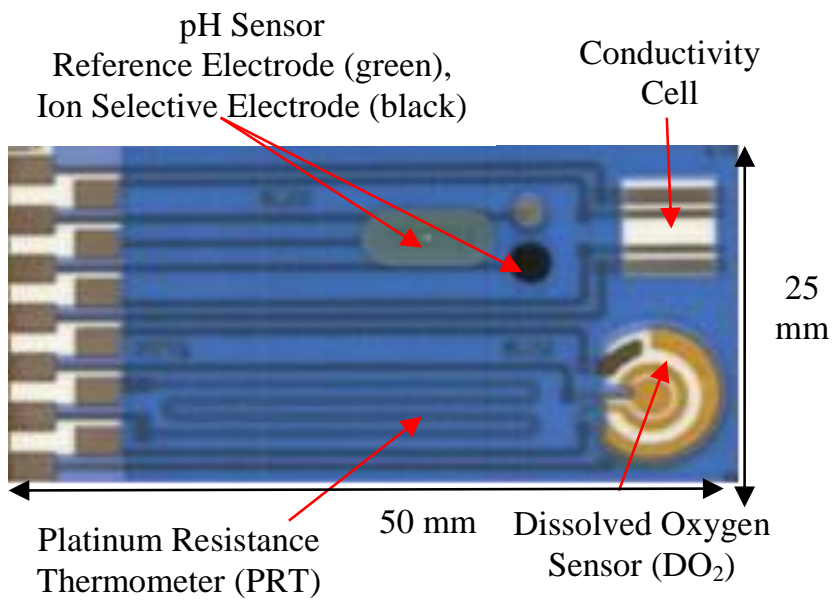

Figure 1: Initial planar conductivity cell design as combined on the same alumina substrate as several other sensors. 
One of the shortcomings of this approach to conductivity measurement however is the non-linearity of the cell constant that results from variable fringing of the electric field within the measurand due to the simple planar arrangement of the sensor electrodes. A further limitation of this planar arrangement for conductivity sensors is that for soil sensing it is often desirable to monitor over a relatively large volume of soil (as compared to liquids) to compensate for any lack of homogeneity in the sample. This requirement dictates a much larger spacing of the electrodes, which can further exacerbate the problems of fringing as a result of the increased electrical path length. One way around this is to maintain the cell constant by also increasing the effective cross-sectional area of the measured sample; however this simple expedient can still prove sensitive to electrode alignment issues. An alternative strategy has been adopted here that exploits a ratio metric symmetry in the electrode arrangement to overcome some of these issues.

\section{BACKGROUND THEORY}

Electrical conductivity $(\sigma)$ is defined as the reciprocal of resistivity $(\rho)$. Resistivity is a property of the material and is defined as:

$$
\rho=\text { R.A/ L }
$$

where $\mathrm{R}$ is the resistance (Ohms), $\mathrm{A}$ is the cross sectional area in contact with the material $\left(\mathrm{m}^{2}\right), \mathrm{L}$ is the length of the material tested $(\mathrm{m})$ and $\rho$ is the resistivity $(\mathrm{Ohm} \mathrm{m})$. Conductivity is measured in Siemens per meter $(\mathrm{S} / \mathrm{m})$ although sometimes it is more conveniently expressed as $\mathrm{mS} / \mathrm{cm}$. Conductivity can therefore be calculated as:

$$
\mathrm{I} / \mathrm{V}=1 / \mathrm{R}=\sigma . \mathrm{L} / \mathrm{A}
$$

where $\mathrm{V}$ is the measured voltage (volts), $\mathrm{I}$ is the drive current (Amperes) and the term L/A is the cell constant $\left(\mathrm{m}^{-1}\right)$.

The specific sensor described here is based on the 4 electrodes method using an alternating square wave current source as the excitation signal. The conventional 4 electrodes method is very simple as shown in figure 2 below.

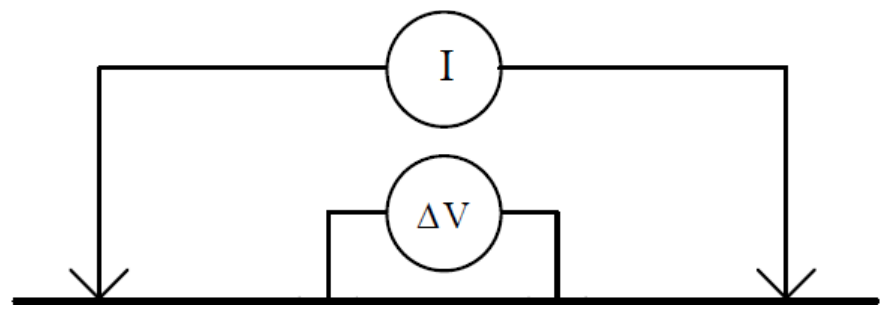

Figure 2: Electrode configuration for the 4 electrodes method

As shown in figure 2, the outer electrodes, which are in contact with the sample measurand, are the current carrying electrode pair and the inner electrodes are the voltage $(\Delta \mathrm{V})$ measuring electrode pair. Assuming that the current passing between the two outer electrodes is equal to the current passing through the inner ones, the electric field developed between the voltage electrodes depends on the electrical impedance of the sample. Using Ohm's law, the impedance of the measurand can be calculated and if a constant current source (I) is used then that impedance is equivalent to the impedance of the measured sample. If the cell constant (L/A) is also known the conductivity of the solution can be calculated using equation (2). However due to fringing of the electric field between the electrodes, these two currents are not the same and hence the cell constant becomes a function of the fringing. The fringing in turn is a function of the conductivity of the measurand, giving rise to non-linearity in the measurement of conductivity.

There are however, several advantages to using the 4 electrodes method including the minimisation of polarisation effects as well as a longer electrode lifetime and a wider measuring range. The use of an alternating current source also minimises any polarisation effect and in particular, the use of low frequencies minimises any errors that might arise due to the effective capacitance of the measurand.

\section{FABRICATION \& GEOMETRIC CONFIGURATION}

An initial design for the described multi-element sensor array utilised a simple 4 electrode planar conductivity cell where the electrodes were made of a high purity platinum ink (shown in figure 1) printed on a ceramic (96\% alumina, Coors Tech) substrate. However due to issues with variable fringing at different frequencies and conductivities the cell geometry was changed to a 3 dimensional model as shown in figure 3 , using the same substrate size and material as before with a spacing distance between opposing electrodes of 15 $\mathrm{mm}$. In order to decrease fabrication costs, a fritted gold ink (ESL-8844, Electro Science) was used instead of platinum.
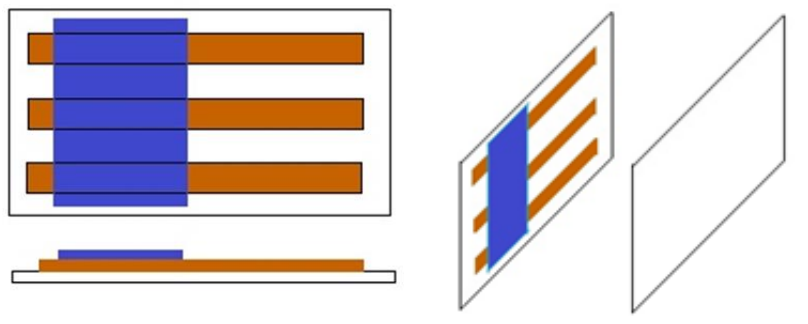

Figure 3: New conductivity cell configuration and geometry.

This approach also facilitated the printing of one half of the conductivity cell onto the back of the existing substrate design with an identical electrode pattern printed on a second substrate mounted opposite and facing the first. There are three gold electrodes on each substrate and a small protective dielectric layer. Table 1 shows the fabrication details of the inks used along with their firing temperatures and times.

Table 1: Ink details, temperatures and times.

\begin{tabular}{cccccc}
\hline Layer & Paste & $\begin{array}{c}\text { Drying } \\
\text { temperature } \\
\left({ }^{\circ} \mathrm{C}\right)\end{array}$ & $\begin{array}{c}\text { Drying } \\
\text { time } \\
(\mathrm{min})\end{array}$ & $\begin{array}{c}\text { Firing } \\
\text { temperature } \\
\left({ }^{\circ} \mathrm{C}\right)\end{array}$ & $\begin{array}{c}\text { Firing time } \\
(\mathrm{min})\end{array}$ \\
\hline $\begin{array}{c}\text { Gold } \\
\text { conductor }\end{array}$ & ESL-8844 & 125 & $10-15$ & 850 & $\sim 45$ \\
$\begin{array}{c}\text { Dielectric } \\
\text { insulator }\end{array}$ & ESL-4905-C & 125 & $10-15$ & 850 & $\sim 45$ \\
\hline
\end{tabular}


The dielectric layer (ESL-4905-C, Electro Science) is used to isolate the wire connections from the measurand and to expose the correct surface area of the electrodes. The dimensions for each of the exposed electrodes are $27 \mathrm{~mm} \times 4$ $\mathrm{mm}$ and the distance between each electrode on the same substrate is approximately $5 \mathrm{~mm}$. The 2 outer electrode pairs in the conductivity cell are used to drive current through the cell while the inner electrode pair is used to measure the resulting voltage drop across the measurand. Using this geometry any fringing will be minimised because of the positioning of the measuring electrodes between the two oppositely driven outer electrode pairs and also any rotation of the two substrates relative to one another will be cancelled out. Figure 4 shows a photograph of the sensor array mounting arrangement used for testing the device. The supporting structure for the sensor substrates was manufactured using a commercial biodegradable polymer material on a $3 \mathrm{D}$ printer.

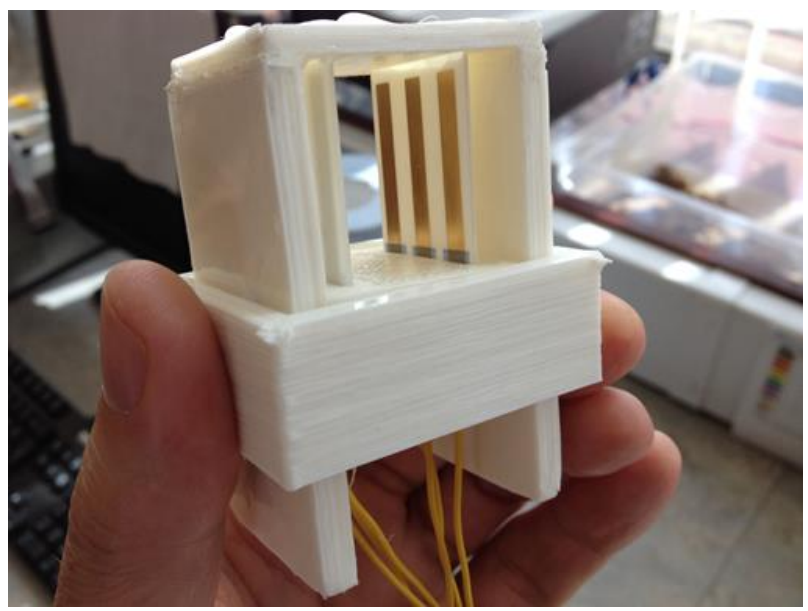

\section{Figure 4: Mounting arrangement for sensor array}

\section{EXPERIMENTAL SETUP \& INSTRUMENTATION}

The thick film sensor array is connected to a custom designed low power interface circuit implemented as a printed circuit board (PCB) of roughly similar dimensions to the sensor array itself, as shown in figure 5 .

The interface circuits have been designed to produce continuous dc voltages that correspond to the real-time measured values of $\mathrm{pH}$, dissolved oxygen, temperature and conductivity in such a way that they can be easily interfaced to a data logger or microprocessor analogue to digital converter. The PCB carries various circuit board jumpers and adjustable components to allow gain setting and offset compensation for easy calibration of the various sensors on the array to allow maximum flexibility of use.
The conductivity interface circuit allows for drive signal frequencies in the range from $100 \mathrm{~Hz}$ to $5 \mathrm{kHz}$ and also allows varying of the drive current amplitude up to a maximum of $4 \mathrm{~mA}$. The drive current signal used is a simple square wave and the resulting input square wave voltage is converted to a single ended dc voltage by a multiplexer/chopper circuit. All the results presented here were obtained by connecting the interface PCB to a custom designed data logger provided by Universidad de Valencia. The temperature was monitored to be approximately $22 \pm$ $2{ }^{\circ} \mathrm{C}$ throughout the tests.

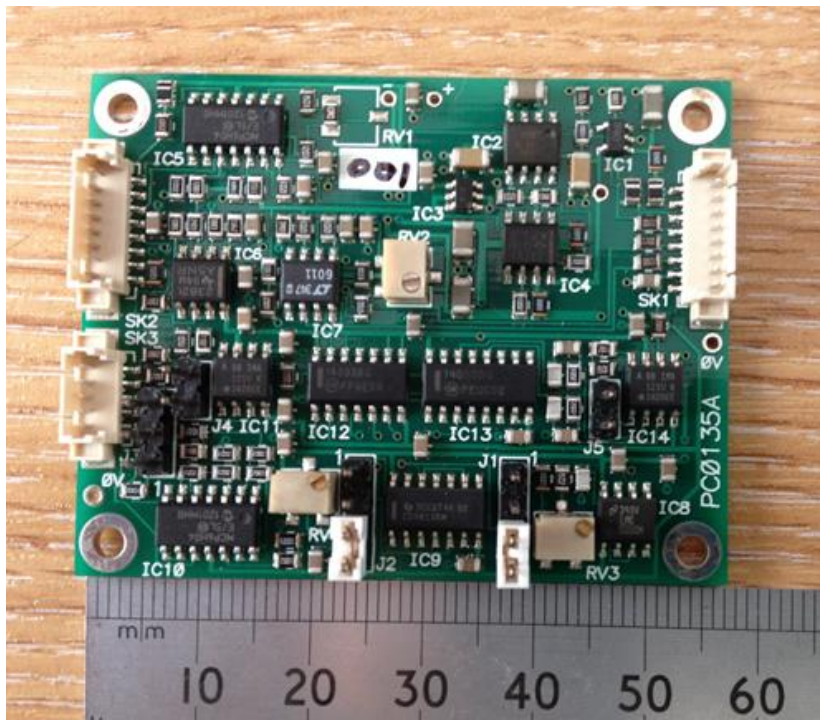

Figure 5: Sensor array interface circuit

For initial evaluation purposes the conductivity sensor was tested in different conductivity solutions ranging from 0.2 to $4 \mathrm{mS} / \mathrm{cm}$. The different test solutions were prepared by dissolving potassium chloride $(\mathrm{KCl})(\mathrm{BDH} 101984 \mathrm{~L}$ AnalaR) in distilled water to a specific molarity for each conductivity, which was then measured for confirmation purposes using a commercially obtained conductivity meter (HI 993310). The sensor was tested over a range of different drive current levels in each of the test solutions. A frequency sweep over the full range $(100 \mathrm{~Hz}$ to $5 \mathrm{kHz})$ was also carried out in a conductivity test solution of $1 \mathrm{mS} / \mathrm{cm}$.

\section{RESULTS \& DISCUSSION}

A plot of sensor output voltage versus reciprocal of conductivity for various levels of drive current is shown in Figure 6. Apart from the highest tested level of drive current $(4 \mathrm{~mA})$ with the lowest conductivity solution $(0.2 \mathrm{mS} / \mathrm{cm})$ where the signal exceeded the dynamic range of the interface circuit, all other readings were within the range of the sensor. 


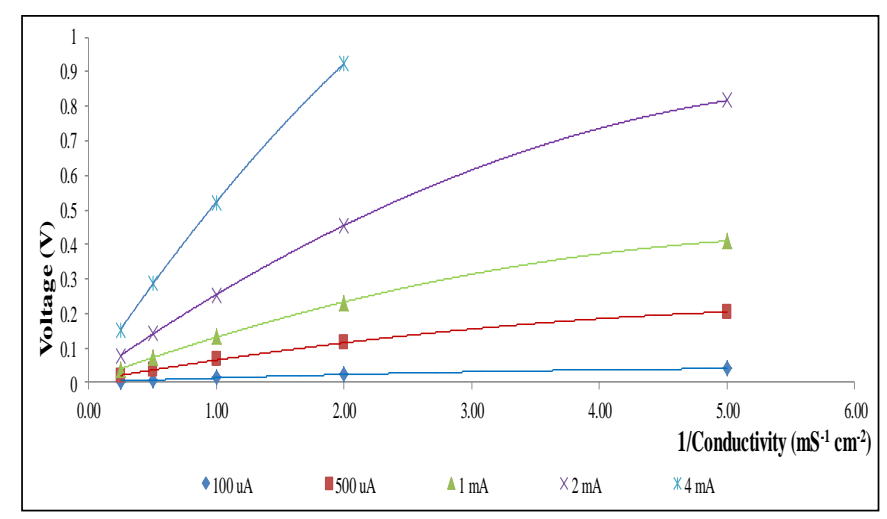

\section{Figure 6: Sensor output voltage versus reciprocal of conductivity for different levels of drive current}

These data were then used to compute the sensor cell constant $\left(\mathrm{cm}^{-1}\right)$ for each value of conductivity test solution, as shown plotted in Figure 7. For different levels of drive current the cell constant was found to be very repeatable, as evidenced by the plots.

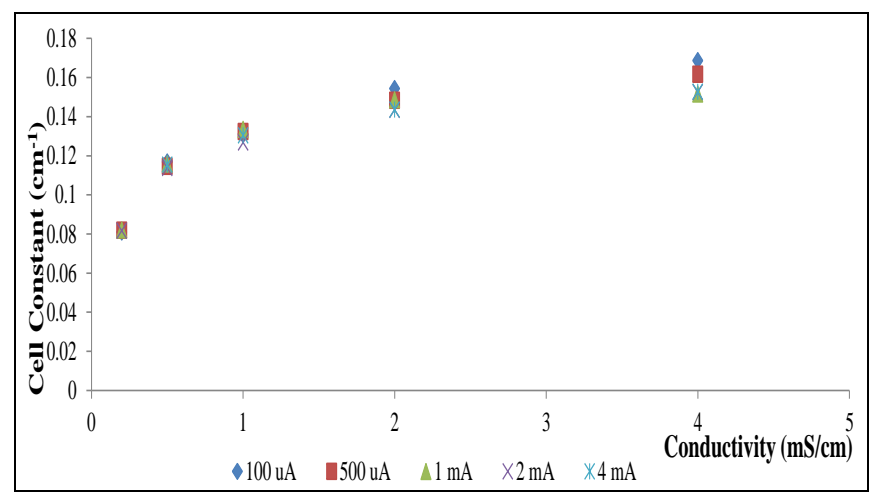

\section{Figure 7: Calculated cell constant versus conductivity} for different levels of drive current

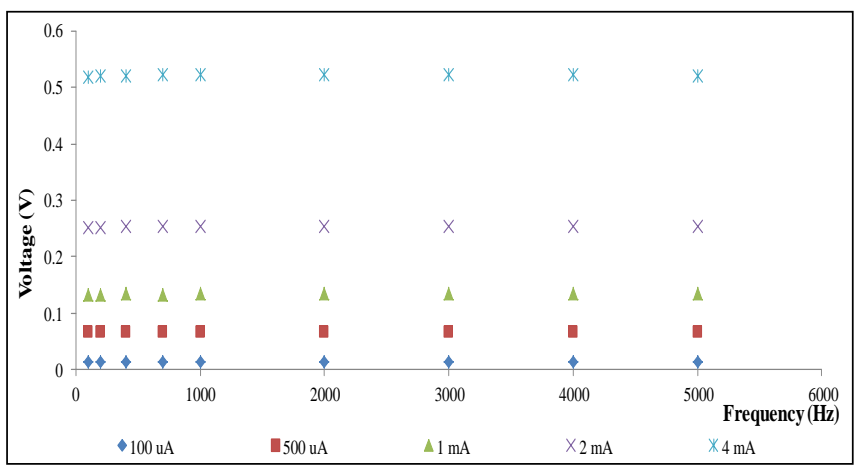

Figure 8: Sensor output voltage versus frequency for different levels of drive current
Varying the frequency of the square wave drive signal did not have any significant effect on the measured output voltages from the sensor in a constant conductivity solution of $1 \mathrm{mS} / \mathrm{cm}$, as is evident in Figure 8.

\section{CONCLUSIONS}

Initial results from testing of the sensor are encouraging in that the device displays a far more linear response over a wider range of conductivities than its predecessor used in the $\mathrm{TF}$ sensor array shown in Figure 1. The new device described here is currently being used to very good effect in a range of experiments concerned with the monitoring of soil structures, where its output is being correlated with soil water content as measured by other instruments, in a range of different soil porosities. Based on the preliminary results reported here some refined electrode geometries are currently in fabrication and will be investigated and their electric fields modelled with the results being reported in a future publication.

\section{REFERENCES}

[1] http://www.reading.ac.uk/geographyandenvironmentalscience/Resear ch/ESS/ges-FUSE.aspx

[2] Hak-Jin Kim, Kenneth A. Sudduthb, John W. Hummelb, "Soil macronutrient sensing for precision agriculture", J. Environ. Monit. vol. 11, p. 1810-1824, 2009.

[3] J. Bouma, "Land quality indicators of sustainable land management across scales", Agriculture, Ecosystems and Environment, vol. 88, p. 129-136, 2002

[4] M.A. Arshada, S. Martinb, "Identifying critical limits for soil quality indicators in agro-ecosystems", Agriculture, Ecosystems and Environment, vol. 88, p. 153-160, 2002.

[5] Misac N. Nabighian, "Electromagnetic methods in applied geophysics", Volume 1: Theory, United States of America: Society of explorationg geophysicists, 2006.

[6] Fritz Scholz, "Electroanalytical Methods: Guide to Experiments and Applications" United States of America: Springer, 2010

[7] D. A. Robinson,* C. S. Campbell, J. W. Hopmans, B. K. Hornbuckle, S. B. Jones, R. Knight, F. Ogden, J. Selker, and O. Wendroth, "Soil Moisture Measurement for Ecological and Hydrological WatershedScale Observatories: A Review", Vadose Zone Journal, Vol. 7, No 1, pages 358-389, 2008.

[8] Shmulik P. Friedman, "Soil properties influencing apparent electrical conductivity: a review", Computers and Electronics in Agriculture, Vol. 46, Issue 1-3, pages 45-70, 2005.

[9] S. J. Zegelin, I. White, D. R. Jenkins, "Improved Field Probes for Soil Water Content and Electrical Conductivity Measurement Using Time Domain Reflectometry", Water Resources Research, Vol. 25, No. 11, Pages 2367-2376, 1989.

[10] M. A. Hilhorst, "A Pore Water Conductivity Sensor", Soil Science Society of America Journal, Vol. 64 No. 6, p. 1922-1925, 2000.

[11] Wei, Yaoguang, Wang, Jianqing, Li, Daoliang, Ding, Qisheng, "Design of Intelligent Conductivity Meter Based on MSP430F149", 3rd IFIP TC 12 International Conference of Computer and Computing Technologies in Agriculture, 2009.

[12] Atkinson JK, Glanc M, Prakorbjanya M, Sophocleous M, Sion RP, Garcia-Breijo E. Thick film screen printed environmental and chemical sensor array reference electrodes suitable for subterranean and subaqueous deployments. Microelectronics International. 2013;30(2):92-8 